\title{
Biomechanical study of extramedullary and intramedullary fixation in the treatment of unstable intertrochanteric reversed-tilt fractures of the femur
}

\author{
Guo-Liang $\mathrm{Lu}^{1 \#}$, Song-Jun $\mathrm{Li}^{2 \#}$, Wen-Xue $\mathrm{Li}^{3}$ \\ ${ }^{1}$ Department of Orthopedic Trauma, Foshan Hospital of TCM (The Eighth Affiliated Hospital of Guangzhou University of Traditional Chinese \\ Medicine), Foshan, China; ${ }^{2}$ Department of Orthopedics, the Fifth Affiliated Hospital of Zunyi Medical University, Zhuhai, China; ${ }^{3}$ Department of \\ Orthopedics, Dongying Hospital of Traditional Chinese Medicine, Dongying, China \\ Contributions: (I) Conception and design: GL Lu, SJ Li; (II) Administrative support: WX Li; (III) Provision of study materials or patients: All authors; \\ (IV) Collection and assembly of data: All authors; (V) Data analysis and interpretation: All authors; (VI) Manuscript writing: All authors; (VII) Final \\ approval of manuscript: All authors. \\ "These authors contributed equally to this work. \\ Correspondence to: Wen-Xue Li. Bachelor of Medicine, Associate Chief Physician, Department of Orthopedics, Dongying Hospital of Traditional \\ Chinese Medicine, No. 107, Beier Road, Dongying District, Dongying, China. Email: lwxgjz10778@sina.com.
}

Background: To investigate the efficacy of the $135^{\circ}$ hip screw, $95^{\circ}$ intramedullary hip screw (IMHS) and $95^{\circ}$ hip screw in the treatment of intertrochanteric reverse dip fracture of the femur.

Methods: We retrospectively analyzed 125 matched pairs of human femurs (median age 64 years) which were osteotomized at a $33^{\circ}$ angle in the left femur and extended downward from the minor trochanter to simulate a reverse oblique intertrochanteric fracture. The right femur served as a control. The left femur $(\mathrm{n}=4)$ was implanted with a $135^{\circ}$ hip screw, $95^{\circ}$ hip screw, or IMHS. A strain detector was placed distal to the fracture site to monitor fragment strain. The lateral displacement of the proximal femur was measured by a linear variable differential transformer. An Instron tester measured stiffness, strain, and lateral displacement at $25^{\circ}$ adduction, and $90^{\circ}$ adduction with vertical loads on the femoral head. A $2 \mathrm{~cm}$ gap was then formed at the fracture site to simulate comminution and the mechanical test was repeated.

Results: Before the formation of the gap, there was no significant difference in stiffness among different bone structures $(\mathrm{P}>0.05)$, but after the formation of the gap, the stiffness of all the adduction structures decreased $(\mathrm{P}=0.03)$, and the difference in adduction was statistically significant $\left(135^{\circ}\right.$ hip screw: $46.6 \% \pm 3 \%$; $95^{\circ}$ hip screw: $22.9 \% \pm 2 \%$; IMHS: $53.7 \% \pm 7.8 \%$; $\left.\mathrm{P}<0.05\right)$. Similar results were found for the abduction and buckling positions. There was no significant difference in the lateral displacement of the gap before $(\mathrm{P}=0.92)$ and after $(\mathrm{P}=0.26)$, but a significant difference in the failure load was found $\left(135^{\circ}\right.$ hip screw: $1,222 \pm 560 \mathrm{~N}$; $95^{\circ}$ hip screw: $2,566 \pm 283 \mathrm{~N}$; IMHS: 4,644 $\pm 518 \mathrm{~N}$; P=0.02).

Conclusions: There was no statistically significant difference in stiffness among different structures $(\mathrm{P}>0.05)$. However, in the presence of gaps, IMHS bone implant structures are much stiffer than $135^{\circ}$ and $95^{\circ}$ structures and have a greater destructive load.

Keywords: Hip screw; biomechanics; intramedullary nail; intertrochanteric reverse dip fracture; retrospective study

Submitted Nov 16, 2021. Accepted for publication Feb 18, 2022.

doi: $10.21037 / \mathrm{atm}-22-93$

View this article at: https://dx.doi.org/10.21037/atm-22-93 


\section{Introduction}

Intertrochanteric fractures of the femur are common, leading to significant morbidity and mortality. The functional outcomes of patients with intertrochanteric fractures are surprisingly poor, with significant limitation of mobility (1-3). Interfemoral rotor fractures have a very high incidence in the elderly population, especially in the elderly patients with osteoporosis. Due to its high disability rate and case fatality rate, it poses a serious threat to the life and health of elderly patients (4). The epidemiological trends suggest that the incidence of interrotor fractures will increase further in the future, which also poses a serious challenge to the global healthcare system. Standardizing the treatment of femoral interrotor fractures with different types is also a hot topic for orthopedic doctors today. Timely surgery as well as early postoperatively functional exercise are key to reducing high mortality (5). Interfemoral rotor fracture refers to the fracture from the base of the femoral neck to the area of the small rotor level (6). It belongs to the hip capsule fracture. It is a common hip fracture and is often seen in elderly patients (7). In this study, a reverse dip intertrochanter fracture was defined as a two-part fracture extending downward from the lower direction of the lesser trochanter.

The best fixation device for reversibly inclined intertrochanteric fractures is an internal fixation device that can resist the tendency of proximal fracture to transition, rotation, and varus (8). Intramedullary fixation has gradually replaced dynamic hip screw (DHS) for its advantages of strong stability, simple operation, less damage and less bleeding. Hemoglobin $(\mathrm{Hb})$ decreased after surgery, and $\mathrm{Hb}$ could not be restored to normal level soon after blood transfusion, resulting in large unplanned blood consumption. The best way to fix a reverse-inclined intertrochanteric fracture is to use an implant that the proximal pronation and rotation of the fracture. As the global population ages, the incidence of interfemoral rotor fractures is increasing, accounting for more than half of hip fractures, and over $90 \%$ of patients with clinical interfemoral rotor fractures are over 65 years. Patients with such fractures are often accompanied by severe osteoporosis, minor trauma can cause interrotor fractures, and interrotor fractures have a high disability rate and case fatality rate (9). A recent retrospective clinical study by Baral et al. (10) intertrochanteric reverse dip fracture of the femur concluded that $95^{\circ}$ extramedullary fixation was superior to other fixation devices. Luo et al. (11) conducted a prospective, randomized clinical study which found that intramedullary devices were superior to $95^{\circ}$ extramedullary devices. However, there are still few studies comparing the biomechanical properties of different fixation devices inclined intertrochanteric fractures (12). It can be divided into stable and unstable fractures in Evans typing, which is mainly based on the integrity and continuity of the posterior inner wall cortex. After the stable interrotor fracture, the internal wall is intact or with a very small displacement, and the unstable interrotor fracture after the internal wall is comminuted (13). There is also a special classification in this classification. Type $\mathrm{R}$, whose fracture line is antioblique, also known as inter-rotor fracture.

We present the following article in accordance with the STROBE reporting checklist (available at https://atm. amegroups.com/article/view/10.21037/atm-22-93/rc).

\section{Methods}

\section{Patients enrolled in the study}

The patient medical records of 125 pairs of matched femurs (median age: 64, 55-82) were collected from the Dongying Hospital of Traditional Chinese Medicine. None of the enrolled patients had a history of femur malignancy, fracture, or internal fixation. Bone quality was determined by radiographs of the femur using Singh's index. The included medical records detailed the efficacy of different graft materials in three groups of 125 patients with different treatment regimens. All procedures performed in this study involving human participants were in accordance with the Declaration of Helsinki (as revised in 2013). The study was approved by the Ethics Committee of the Dongying Hospital of Traditional Chinese Medicine (No. 2021-038). Individual consent for this retrospective analysis was waived.

\section{Surgical procedure}

This study used an appropriate implant to fix the left femur, fluoroscopic assistance to implant the implant, and ensured that the lag screw was in the best position within the femoral head. The bone graft structure was examined to ensure that the implant was placed correctly. The lag screw was placed in the center of the head, and using cyanoacrylate adhesive, the uniaxial strain gauge (EA-06$125 \mathrm{AC}-350$ ) was bonded to the lateral side of the control and implant diaphysis in several locations. 
Table 1 Measurement data of fixed structure before clearance

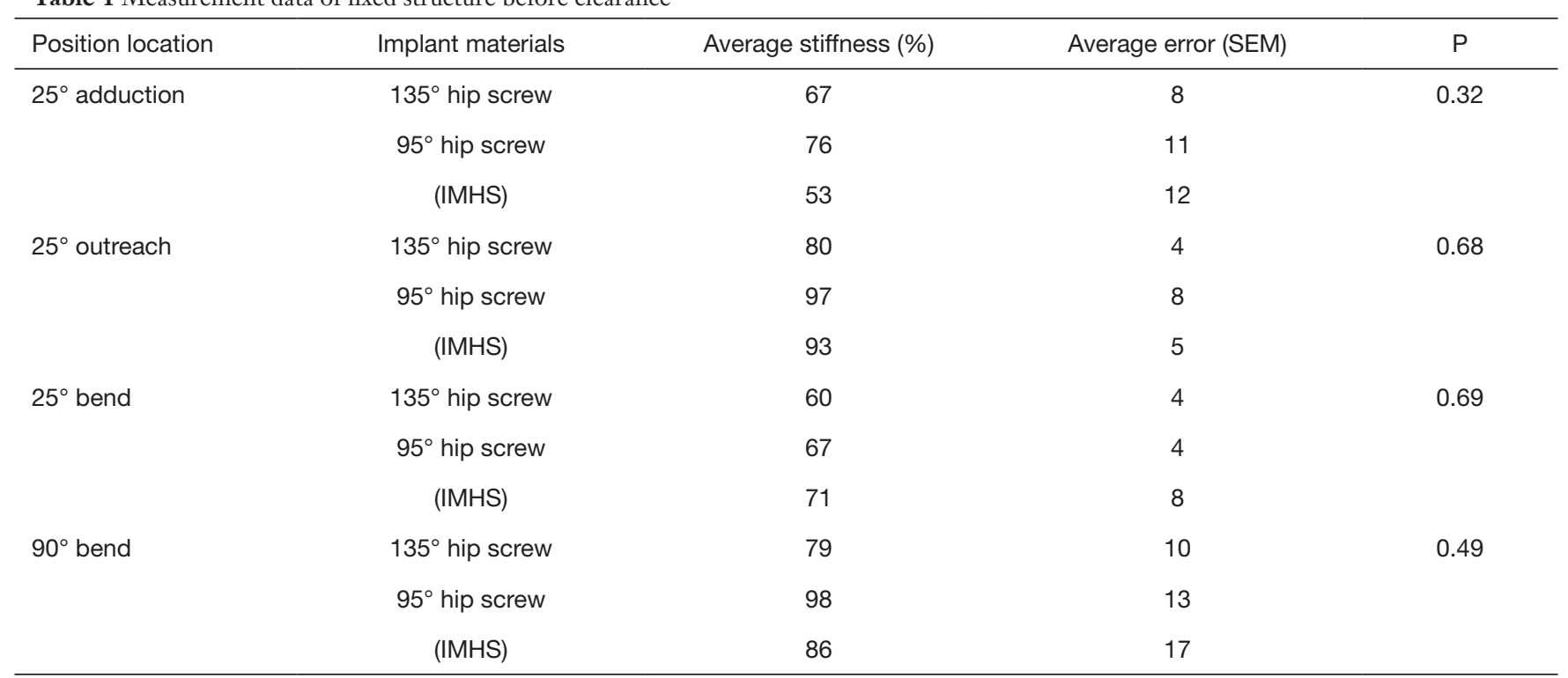

SEM, standard error of mean; IMHS, intramedullary hip screw.

\section{Data sorting}

All data were reported as mean \pm standard error of mean (SEM), and the results of the bone graft structure were calculated by dividing. All the specimens of the preclearance stiffness test and post-clearance stiffness test remained within the online elastic range, and the average linear coefficients were $R^{2}>0.95$ and $R^{2}>0.90$, respectively. Strain was reported as a non-normalized value that distinguishes tension from compression. For any significant differences identified in each analysis of variance (ANOVA) $(\mathrm{P}<0.05)$.

\section{Statistical analysis}

SPSS 21.0 software (IBM) was used for statistical analysis of all data in this study. The measurement data were expressed as mean \pm standard deviation. $T$-tests were used for comparisons between two groups, and one-way ANOVA was used for comparisons between multiple groups. $\mathrm{P}<0.05$ was considered to be statistically significant.

\section{Results}

\section{Stiffness measurement}

For the intact control femur group, the stiffness results (SEM) for the $135^{\circ}$ hip screw were $25^{\circ}$ adduction
$1,535.81 \pm 111.68 \mathrm{~N} / \mathrm{mm}, 25^{\circ}$ abduction $315.29 \pm 6.71 \mathrm{~N} / \mathrm{mm}$, $25^{\circ}$ forward bend $564.20 \pm 28.26 \mathrm{~N} / \mathrm{mm}$, and $90^{\circ}$ flexion $44.94 \pm 2.39 \mathrm{~N} / \mathrm{mm}$. The stiffness results for the $95^{\circ}$ hip screw were $25^{\circ}$ adduction $1,864.01 \pm 185.05 \mathrm{~N} / \mathrm{mm}, 25^{\circ}$ forward bend $581.96 \pm 95.59 \mathrm{~N} / \mathrm{mm}$, and $90^{\circ}$ forward bend $45.02 \pm 5.02 \mathrm{~N} / \mathrm{mm}$. The stiffness results for intramedullary hip screw (IMHS) were $25^{\circ}$ adduction $1,678.19 \pm 192.86 \mathrm{~N} / \mathrm{mm}$, $25^{\circ}$ abduction $282.70 \pm 21.90 \mathrm{~N} / \mathrm{mm}, 25^{\circ}$ forward bend $477.99 \pm 27.85 \mathrm{~N} / \mathrm{mm}$, and $90^{\circ}$ forward bend $41.78 \pm 2.34 \mathrm{~N} / \mathrm{mm}$ (Table 1). After the segmentation gap was formed, the stiffness of all implanted structures decreased $(\mathrm{P}=0.03)$, and the stiffness of different implanted structures was significantly different $(\mathrm{P}=0.046$; Table 2$)$. All $135^{\circ}$ hip screw implants failed during pre-treatment after gap formation. Tests at $90^{\circ}$ flexion showed significant differences in hardness between implants after fragmentation $(\mathrm{P}=0.0004)$, with $135^{\circ}$ hip screws being stiffer than $95^{\circ}$ hip screws $(\mathrm{P}=0.002)$ and $95^{\circ}$ hip screws being stiffer than IMHS $(\mathrm{P}=0.02)$. See Figure 1.

\section{Lateral displacement measurement}

In this study, this was performed before and after the fragmentation gap was created in all implants at $25^{\circ}$ adduction. There was no difference in proximal fracture segment displacement before and after fracture space formation ( $\mathrm{P}=0.92$; Table 3). After space formation, the 
Table 2 Measurement data of fixed structure after clearance

\begin{tabular}{|c|c|c|c|c|}
\hline Position location & Implant materials & Average stiffness (\%) & Average error (SEM) & $\mathrm{P}$ \\
\hline \multirow{2}{*}{$25^{\circ}$ adduction } & $95^{\circ}$ hip screw & 23 & 2 & \\
\hline & (IMHS) & 57 & 8 & \\
\hline \multirow[t]{2}{*}{$25^{\circ}$ outreach } & $135^{\circ}$ hip screw & 73 & 7 & $0.020^{*}$ \\
\hline & (IMHS) & 59 & 3 & \\
\hline \multirow[t]{3}{*}{$25^{\circ}$ bend } & $135^{\circ}$ hip screw & 58 & 8 & $0.040^{\star}$ \\
\hline & $95^{\circ}$ hip screw & 29 & 3 & \\
\hline & (IMHS) & 57 & 6 & \\
\hline $90^{\circ}$ bend & (IMHS) & 45 & 4 & \\
\hline
\end{tabular}

*, P<0.05; SEM, standard error of mean; IMHS, intramedullary hip screw.

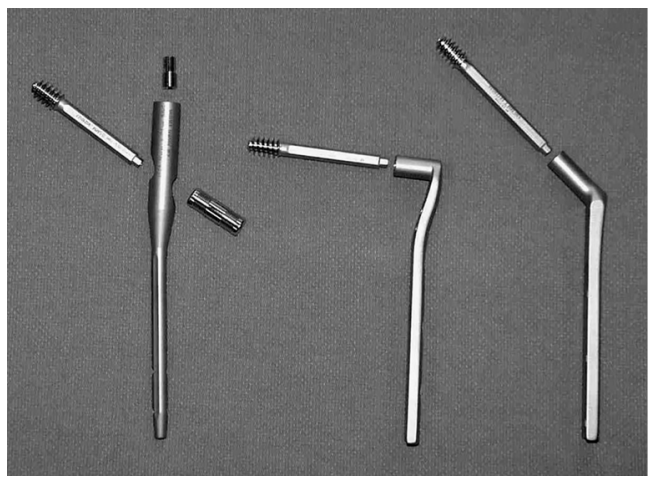

Figure 1 The IMHS, $95^{\circ}$ hip screw, and $135^{\circ}$ hip screw devices. IMHS, intramedullary hip screw. femurs of the $95^{\circ}$ hip screw implants tended to shift laterally.

\section{Stress measurement}

Under the femoral head load of 1,000 N, the stress changes at all positions were recorded. It was no difference in the implant at $25^{\circ}$ abduction, $25^{\circ}$ buckling, or $90^{\circ}$ buckling $(\mathrm{P}>0.05)$. Proximal strain gauge analysis at $25^{\circ}$ adduction revealed a reduction in tensile strain after space formation. This resulted in a reduction of the implant was subjected to major gravity after the fragmentation gap had formed. The distal strain gauge of all implants was compressed during

Table 3 Measurement data of lateral displacement along the fracture before and after fracture formation (\%)

\begin{tabular}{|c|c|c|c|c|}
\hline Position location & Implant materials & Average stiffness (\%) & Average error (SEM) & $\mathrm{P}$ \\
\hline \multirow{2}{*}{ Before clearance } & $95^{\circ}$ hip screw & 79 & 19 & \\
\hline & (IMHS) & 84 & 25 & \\
\hline \multirow[t]{2}{*}{ After clearance } & $135^{\circ}$ hip screw & 41 & 24 & 0.26 \\
\hline & (IMHS) & 77 & 28 & \\
\hline
\end{tabular}

SEM, standard error of mean; IMHS, intramedullary hip screw. 
the $25^{\circ}$ adduction test. The distal strain gauge showed that the implant was exerting stress on the femoral shaft. But compressive stress increased with the crevices at the fracture site and at the distal end. Compared with extramedullary implants, the stress of IMHS at the distal end of the implant was not significantly increased, and there was no significant difference between the strain of IMHS at each position and the distal locking screw tip $(\mathrm{P}>0.05)$. All the patients were followed up for 3 months.

\section{Discussion}

Interfemoral rotor fracture is one of the most common fractures in orthopedic clinical work (14). Due to high disability and lethality rate, the treatment of such fracture needs early surgery. The purpose of the operation is: (I) to reduce the pain; (II) to enable the patient to recover as soon as possible; (III) to reduce the complications caused by long-term bed (15). Although a variety of implantable internal materials have been developed, none is available for all types of fracture. And orthopaedic surgeons should make reasonable choices based on individual patient differences and the different typing of the fracture. Of course, there are inevitable complications, clinicians should constantly improve the surgical skills and be familiar with the use of different internal fixation materials so as to minimize the occurrence of surgical complications, which is also the key to determine the success of the operation.

This may result in implant bone construction failure and neutralization of the distal fracture mass (16-18). This small area is subjected to considerable pressure (19). Failure of the $135^{\circ}$ hip screw occurs in cortical fractures. Therefore, the success of $135^{\circ}$ hip screw treatment for this fracture (20), and this type of internal fixation may be better for reverse dip fractures with greater distal extension. Therefore, it is necessary to select treatment and rehabilitation programs based on rapid post-admission risk assessment for elderly patients with intertrochanteric fractures. The patient's age, cardiopulmonary function, nutritional status, liver function, renal function, blood glucose and blood pressure levels, electrolyte balance, breath-holding tolerance and pre-injury activity state all directly affect the patient's anesthesia, operation tolerance and postoperative rehabilitation. Intramedullary nail has obvious biomechanical advantages in the treatment of intertrochanteric fracture of femur. The main nail and the screw in the femoral head and neck form a three-point fixation, which can share the load and reduce the bearing moment, thus reducing the bending pressure of the intramedullary nail internal fixation and reducing the deformation or fracture of the intramedullary nail. However, there are still deficiencies in the treatment of osteoporotic fractures with intramedullary nail fixation. The main complications include nail tail shaft fracture, femoral head varus collapse, femoral neck shortening, etc. These complications are related to the design and placement of intramedullary nailing (21-24). After the intervertebral space was formed, the stiffness of the $95^{\circ}$ hip screw at $25^{\circ}$ adduction was significantly lower than that of the IMHS (25). This suggests that $95^{\circ}$ hip screws and IMHS provide the same stable structure when anatomic reduction can be achieved, and IMHS may provide a more stable structure if the fracture construction and the talus breaks (26). IMHS is the hardest implant at $90^{\circ}$ flexion.

In recent years, with the continuous optimization of endoplants and the improvement of doctors' surgical skills, the treatment effect of interrotor fractures has been significantly improved (27). The commonly used sliding hip screws, also known as compression hip screws or DHS, have evolved over the years. The early screw does not have the effect of compression on the broken end of hip fracture, because of the lack of compression on the broken end, it is very easy to appear the phenomenon of bone disunion and internal fixation failure. However, the advent of DHS makes up for this deficiency, and the compression effect of lag screws can make the fractured ends tightly stick together, reducing the occurrence of bone nonunion and internal fixation failure (28). The $95^{\circ}$ hip screw was fixed to the lateral cortex, while the IMHS impinged on the lateral cortex within the intramedullary canal. Thus, when calcaneal support is lost at the fracture site, both implants change the physiological pull present near the femoral shaft into compression force. Moktar et al. (29) noted increased compression of the lateral cortex and increased fracture instability. The use of DHS requires the integrity of the large rotor lateral wall of the femur, which is an excellent implant for the complete and stable lateral wall. The nail plate structure can convert the shear force of the fracture into the axial force, which is consistent with the characteristics of human biomechanics. At the same time, the power hip screw can stably maintain the neck dry angle, which can effectively prevent the occurrence of hip valgus. Hiragami et al. (30) reported that IMHS distal fractures are ineffective treatment in biomechanical testing. The proximal abaxial intramedullary nail (PFNA) is a special and new intramedullary fixation system developed by AO. It is improved on the basis of PFN and has better biomechanical 
and mechanechanical effects than PFN. PFNA also has its own disadvantages. If the outer wall of the large rotor is heavily damaged, the support of the spiral blade, which can lead to internal fixation failure (31). In this study, it was found that the treatment of intertrochanteric reverse tilt fracture of the femur depends on the degree of fracture comminution and the angle of femur repair. In the absence of bone space, and IMHS hardness with bone space was significant (32). It also has a higher failure load than other structures.

\section{Acknowledgments}

Funding: None.

\section{Footnote}

Reporting Checklist: The authors have completed the STROBE reporting checklist. Available at https://atm. amegroups.com/article/view/10.21037/atm-22-93/rc

Data Sharing Statement: Available at https://atm.amegroups. com/article/view/10.21037/atm-22-93/dss

Conflicts of Interest: All authors have completed the ICMJE uniform disclosure form (available at https://atm. amegroups.com/article/view/10.21037/atm-22-93/coif). The authors have no conflicts of interest to declare.

Ethical Statement: The authors are accountable for all aspects of the work in ensuring that questions related to the accuracy or integrity of any part of the work are appropriately investigated and resolved. All procedures performed in this study involving human participants were in accordance with the Declaration of Helsinki (as revised in 2013). The study was approved by the Ethics Committee of the Dongying Hospital of Traditional Chinese Medicine (No. 2021-038). Individual consent for this retrospective analysis was waived.

Open Access Statement: This is an Open Access article distributed in accordance with the Creative Commons Attribution-NonCommercial-NoDerivs 4.0 International License (CC BY-NC-ND 4.0), which permits the noncommercial replication and distribution of the article with the strict proviso that no changes or edits are made and the original work is properly cited (including links to both the formal publication through the relevant DOI and the license).
See: https://creativecommons.org/licenses/by-nc-nd/4.0/.

\section{References}

1. Hollensteiner M, Sandriesser S, Bliven E, et al. Biomechanics of Osteoporotic Fracture Fixation. Curr Osteoporos Rep 2019;17:363-74.

2. Augat P, Bliven E, Hackl S. Biomechanics of Femoral Neck Fractures and Implications for Fixation. J Orthop Trauma 2019;33 Suppl 1:S27-32.

3. Socci AR, Casemyr NE, Leslie MP, et al. Implant options for the treatment of intertrochanteric fractures of the hip: rationale, evidence, and recommendations. Bone Joint J 2017;99-B:128-33.

4. Kiapour A, Joukar A, Elgafy H, et al. Biomechanics of the Sacroiliac Joint: Anatomy, Function, Biomechanics, Sexual Dimorphism, and Causes of Pain. Int J Spine Surg 2020;14:3-13.

5. Wang Y, Ma JX, Yin T, et al. Correlation Between Reduction Quality of Femoral Neck Fracture and Femoral Head Necrosis Based on Biomechanics. Orthop Surg 2019;11:318-24.

6. Sheehan KJ, Williamson L, Alexander J, et al. Prognostic factors of functional outcome after hip fracture surgery: a systematic review. Age Ageing 2018;47:661-70.

7. Bizzoca D, Bortone I, Vicenti G, et al. Gait analysis in the postoperative assessment of intertrochanteric femur fractures. J Biol Regul Homeost Agents 2020;34:345-351. Congress of the Italian Orthopaedic Research Society.

8. Chen HB, Wu HB, Chen M, et al. Design and biomechanical study of slide-poking external fixator for hip fracture. J Int Med Res 2020;48:300060520950934.

9. Lu Y, Uppal HS. Hip Fractures: Relevant Anatomy, Classification, and Biomechanics of Fracture and Fixation. Geriatr Orthop Surg Rehabil 2019;10:2151459319859139.

10. Baral P, Chaudhary P, Shah AB, et al. Outcome of Proximal Femoral Nail Antirotation II fixation of Peritrochanteric Fracture of Femur. J Nepal Health Res Counc 2020;18:301-6.

11. Luo Y, Yang H. Comparison of femur stiffness measured from DXA and QCT for assessment of hip fracture risk. J Bone Miner Metab 2019;37:342-50.

12. Wang K, Kenanidis E, Miodownik M, et al. Periprosthetic fracture fixation of the femur following total hip arthroplasty: A review of biomechanical testing - Part II. Clin Biomech (Bristol, Avon) 2019;61:144-62.

13. Kim KH, Kang MS, Lim EJ, et al. Posterior Sagging After Cephalomedullary Nailing for Intertrochanteric 
Femur Fracture is Associated with a Separation of the Greater Trochanter. Geriatr Orthop Surg Rehabil 2020;11:2151459320946013.

14. Nie S, Li M, Ji H, et al. Biomechanical comparison of medial sustainable nail and proximal femoral nail antirotation in the treatment of an unstable intertrochanteric fracture. Bone Joint Res 2020;9:840-7.

15. Wu HF, Chang CH, Wang GJ, et al. Biomechanical investigation of dynamic hip screw and wire fixation on an unstable intertrochanteric fracture. Biomed Eng Online 2019;18:49.

16. Yang Y, Komisar V, Shishov N, et al. The Effect of Fall Biomechanics on Risk for Hip Fracture in Older Adults: A Cohort Study of Video-Captured Falls in Long-Term Care. J Bone Miner Res 2020;35:1914-22.

17. Larrainzar-Garijo R, Caeiro JR, Marco M, et al. Experimental validation of finite elements model in hip fracture and its clinical applicability. Rev Esp Cir Ortop Traumatol (Engl Ed) 2019;63:146-54.

18. Crump EK, Quacinella M, Deafenbaugh BK. Does Screw Location Affect the Risk of Subtrochanteric Femur Fracture After Femoral Neck Fixation? A Biomechanical Study. Clin Orthop Relat Res 2020;478:770-6.

19. Ceynowa M, Zerdzicki K, Klosowski P, et al. The early failure of the gamma nail and the dynamic hip screw in femurs with a wide medullary canal. A biomechanical study of intertrochanteric fractures. Clin Biomech (Bristol, Avon) 2020;71:201-7.

20. Huang $X$, Zhang F, Zhang Y. Case series and finite element analysis of PFNA combined with cerclage wire for treatment of subtrochanteric fracture of femur. J Orthop Surg Res 2021;16:70.

21. Marmor M, Liddle K, Buckley J, et al. Effect of varus and valgus alignment on implant loading after proximal femur fracture fixation. Eur J Orthop Surg Traumatol 2016;26:379-83.

22. Polat G, Akgül T, Ekinci M, et al. A biomechanical comparison of three fixation techniques in osteoporotic reverse oblique intertrochanteric femur fracture with fragmented lateral cortex. Eur J Trauma Emerg Surg 2019;45:499-505.

23. Yang XJ, Sang HX, Bai B, et al. Ex Vivo Evaluation of Hip Fracture Risk by Proximal Femur Geometry and Bone Mineral Density in Elderly Chinese Women. Med Sci Monit 2018;24:7438-43.

24. Diaz-Dilernia F, Garcia-Mansilla A, Llano L, et al. Who Restores Hip Biomechanics More Effectively after a Femoral Neck Fracture? Comparison of Total Hip Arthroplasties Performed by Either Hip Surgeons or Orthopaedic Residents. Arthroplast Today 2020;6:736-41.

25. Stoffel K, Zderic I, Gras F, et al. Biomechanical Evaluation of the Femoral Neck System in Unstable Pauwels III Femoral Neck Fractures: A Comparison with the Dynamic Hip Screw and Cannulated Screws. J Orthop Trauma 2017;31:131-7.

26. Jitprapaikulsarn S, Chantarapanich N, Gromprasit A, et al. Single lag screw and reverse distal femur locking compression plate for concurrent cervicotrochanteric and shaft fractures of the femur: biomechanical study validated with a clinical series. Eur J Orthop Surg Traumatol 2021;31:1179-92.

27. Carli AV, Negus JJ, Haddad FS. Periprosthetic femoral fractures and trying to avoid them: what is the contribution of femoral component design to the increased risk of periprosthetic femoral fracture? Bone Joint J 2017;99-B:50-9.

28. Jain MJ, Mavani KJ, Patel D. Role of Provisional Fixation of Fracture Fragments By Steinmann-Pin and Technical Tips in Proximal Femoral Nailing for Intertrochanteric Fracture. J Clin Diagn Res 2017;11:RC01-5.

29. Moktar J, Machin A, Bougherara H, et al. Biomechanical analysis of transverse acetabular fracture fixation in the elderly via the posterior versus the anterior approach with and without a total hip arthroplasty. Proc Inst Mech Eng H 2020;234:966-74.

30. Hiragami K, Ishii J. Embedding the lateral end of the lag screw within the lateral wall in the repair of reverse obliquity intertrochanteric femur fracture. J Int Med Res 2018;46:1103-8.

31. Futamura K, Baba T, Homma Y, et al. New classification focusing on the relationship between the attachment of the iliofemoral ligament and the course of the fracture line for intertrochanteric fractures. Injury 2016;47:1685-91.

32. Bonnaire F, Lein T, Bula P. Trochanteric femoral fractures: anatomy, biomechanics and choice of implants. Unfallchirurg 2011;114:491-500.

(English Language Editor: C. Betlazar-Maseh)

Cite this article as: $\mathrm{Lu}$ GL, Li SJ, Li WX. Biomechanical study of extramedullary and intramedullary fixation in the treatment of unstable intertrochanteric reversed-tilt fractures of the femur. Ann Transl Med 2022;10(4):191. doi: 10.21037/atm$22-93$ 